\title{
Azolla-Anabaena as a Biofertilizer for Rice Paddy Fields in the Po Valley, a Temperate Rice Area in Northern Italy
}

\author{
Stefano Bocchi and Antonino Malgioglio \\ Department of Crop Science, Milan University, Via G. Celoria, 2-20133 Milan, Italy \\ Correspondence should be addressed to Antonino Malgioglio, antonino.malgioglio@unimi.it
}

Received 11 September 2009; Revised 5 January 2010; Accepted 24 February 2010

Academic Editor: Jagdish K. Ladha

Copyright ( $) 2010$ S. Bocchi and A. Malgioglio. This is an open access article distributed under the Creative Commons Attribution License, which permits unrestricted use, distribution, and reproduction in any medium, provided the original work is properly cited.

Azolla is a floating pteridophyte, which contains as endosymbiont the nitrogen-fixing cyanobacterium Anabaena azollae (Nostocaceae family). Widely cultivated in the Asian regions, Azolla is either incorporated into the soil before rice transplanting or grown as a dual crop along with rice. To examine the feasibility of its use in flooded rice fields sited in the Temperate European Areas, we carried out a series of experiments in PVC tanks during 2000-2002 in Po Valley (northern Italy) conditions, to study the growth-development dynamics and the resistance/tolerance to low temperatures and to commonly used herbicides of several different Azolla strains. Three out of five strains tested survived the winter, with an increase in biomass from March to May producing approximately $30-40 \mathrm{~kg} \mathrm{ha}^{-1}$ of nitrogen. One of these strains, named "Milan", emerged as the most resistant to herbicide and the most productive. Of the herbicides tested, Propanil permitted the survival of growing Azolla.

\section{Introduction}

Azolla is a heterosporous pteridophyte, with seven species. It contains, as endosymbiont, Anabaena azollae Strasburger, a nitrogen fixing cyanobacterium (Nostocaceae family). Available bibliographical data on its environmental development are principally related to experiments carried out in Asian countries [1-3]. However, the wide ranges of temperature, humidity, and solar radiation in which the fern flourishes suggest the possibility of using Azolla outside these regions [4].

At 3 million tonnes per year, the EU ranks 17th (0.5\%) amongst world rice producers, but in terms of consumption, with 3.5 million tonnes, the EU ranks only 19th. Rice is produced in specific areas of France, Greece, Italy, Portugal, and Spain. The main areas of cultivation are in the western part of the Po valley in Northern Italy and in the river delta areas, Ebro and Guadalquivir, in Spain. Together these represent $84 \%$ of the total European cultivated area of about 400,000 ha of rice. Cultivation centers such as Vercelli or Lomellina (Italy), Camargue (France), Ebro and Guadalquivir (Spain) tend to possess distinct "rice-related" characteristics: agronomic (specialization, simplification), landscape ("rice landscape"), natural resources (intensification of the resource use), economy and culture. Furthermore, these rice districts are located in reclaimed, marshy areas/ wetlands of high environmental value which are also highly vulnerable, creating a need for sustainable and environmentally sound management techniques.

Rice yields decline with time, as noted by Ladha et al. [5] in long-term experiments carried out in a rice-rice intensive system under tropical conditions, and this is related by the authors to the decrease of the physiological $\mathrm{N}$ use efficiency. Long-term effects of urea and green manure on rice yield and nitrogen balance were also verified in temperate conditions [6] where the nitrogen use efficiency (NUE) was particularly low.

It is particularly important to increase the efficiency of nitrogen use and concomitantly to reduce water pollution, by changing strategies of mineral use and by integrating organic fertilizers in the rice production system. These strategies seem particularly important if we consider the current increase and interest in organic products in all EU States. It is also important to remember that agriculture can play a significant role in the reduction of greenhouse gases, particularly for $\mathrm{CO}_{2}$ if the rice farmers can increase the soil 
stable organic matter and treat agricultural soils as powerful carbon sinks.

In order to make use of the Azolla fern as a practicable biofertilizer even in the high latitudes of the Rice Temperate Areas of Europe, research is required for identifying fern strains with good resistance to both low winter temperatures and to alternating day/night temperatures in spring before the rice sowing period, and to be able to produce the needed quantities to be incorporated in the soil. Moreover, to use the fern as a biofertilizer in conventional farming, not just in organic farming, some resistance to the most popular herbicides is required. In other words, the fern should reach a good growth rate during spring, with a high percentage of nitrogen, and should be quite resistant to the most common herbicides used in the rice areas. Until now, most of the upto-date research on Azolla in rice has been carried out in tropical or subtropical environments [7-9] and there are only a few reports from temperate ones $[10,11]$.

Therefore, this study was carried out in a temperate environment, aimed at (a) comparing different Azolla strains, chosen on the basis of their resistance to low temperatures, (b) analysing the spring growth rate of the most resistant one, (c) determining the concentration of $\mathrm{N}$ in the Azolla before the sowing of rice to evaluate it as rice biofertilizer, and (d) assessing the morphological modification of Azolla in response to treatments with three kinds of commonly used herbicides.

\section{Materials and Methods}

Azolla filiculoides strains considered resistant to low temperatures were acquired from the Biofertilizer Germplasm Collections (BGC) of $\mathrm{N}_{2}$ fixing organisms of the I.R.R.I. (International Rice Research Institute) in the Philippines.

The four BGC strains were compared with another ("Milan") which had previously acclimatized, over several years, to the environmental conditions of the Milan-Pavia province in Italy, located in the European Rice Belt (latitude $\left.45^{\circ} \mathrm{N}\right)$.

The winter experiment, carried out to evaluate cold resistance through growth analysis of the 5 strains, started on Dec. 6th 2000, approximately 50 days after the arrival of the new strains at the experimental site, in a field near the University of Milan.

The study was carried out in PVC tanks $(30 \mathrm{~cm} \mathrm{~h} \times 50 \times$ 40 ), each containing $10 \mathrm{~L}$ of IRRI nourishing solution [7], in deionized water, situated at ground level and protected from rain and snow by a transparent plastic roof located 3-meters above the water surfaces.

Tanks were arranged in three replicates per strain and set in a completely randomized block design. $30 \mathrm{~g}$ of fern were introduced into each tank and the fresh weight was measured every 15 days, until May 23rd 2001 (168 days). Before weighing, the fern was dried with blotting paper. During the entire period, the water lost through evapotranspiration was replenished every day with deionized water and the nutrient content in the solution was continuously controlled and maintained at a constant level.
In all cases, growth proceeded without reaching a surface-limiting condition, where an increase of thickness, due to the leaf growth, could have changed growth dynamics. Total Nitrogen and Carbon contents were determined through dry combustion of 2-8 mg samples, previously oven dried for 4 hours at $105^{\circ} \mathrm{C}$, by means of an elementary NC analyzer (Thermo Quest 1500).

The sample, enclosed in a tin cap, is released from an auto sampler in an oxidation column at $1020^{\circ} \mathrm{C}$ in a helium current; oxygen is then injected to allow instantaneous combustion of the sample.

The Nitrogen and Carbon concentrations in the samples were calculated from the relative area of peaks in the chromatographic traces, using a calibration curve obtained by subjecting a known material, atropine and grapevine leaves, to standard analyses.

Phosphorus concentration was also analyzed for each tank in order to estimate the $\mathrm{P}$ uptake relative to Azolla growth as a guide for the programming of additions to the medium. Observations of morphological variation were carried out to associate the relevant data to the increase of biomass. Variation in colour from green to red to tawny, together with the leaf dimensions and the surface covered by the plants, was used as a stress index.

Based on the results obtained in the first experiment, the most low-temperature resistant strain "Milan" was selected as it showed the highest increase of biomass. This strain alone was used for the second and third experiments. The growth in spring conditions was tested in the following year, in order to assess the potential of Azolla as a biofertilizer at high latitudes in terms of quantity. Five PVC tanks were prepared by adding $10 \mathrm{~g}$ of Azolla to the growth medium, IRRI nourishing solution, and exposed to external environmental conditions for 37 days, from Mar. 22nd to Apr. 28th 2002. Water lost by evapo-transpiration was replaced with deionized water every day.

Fresh weight was evaluated every seven days and weight determinations were made after drying Azolla biomass with blotting paper.

Finally, in a third separate experiment started on Mar. 29th 2002, the same Milan strain was used to assess resistance to the herbicides. The most popular herbicides, Oxadiazon, Propanil, and Cinosulfuron, were distributed on the fern at the rates usually used in the field.

The first two herbicides, normally distributed in nonflooded soil conditions, were applied to vessels $(4 \mathrm{~cm} \mathrm{~h} \times$ $14 \mathrm{~cm} \times 18 \mathrm{~cm}$ ) containing $2 \mathrm{~cm}$ depth of water-saturated soil, whilst the third, typically used in flooded rice fields, was applied in a PVC tank $(30 \mathrm{~cm} \mathrm{~h} \times 50 \times 40 \times)$, filled with 3 $4 \mathrm{~cm}$ of soil and $5 \mathrm{~cm}$ of water over the soil in which the Azolla was floating.

For the treatments on soil, $10 \mathrm{~g}$ of Azolla were inoculated into every vessel, and for the treatment in water we used $20 \mathrm{~g}$ in every tank, because the volume of the latter was greater than that of the former.

The Azolla cultures were prepared the day before the treatment, which was carried out with a small atomizer, using a dose of $2 \mathrm{Lha}^{-1}$ for Oxadiazon, 6 and $12 \mathrm{~L} \mathrm{ha}^{-1}$ for 


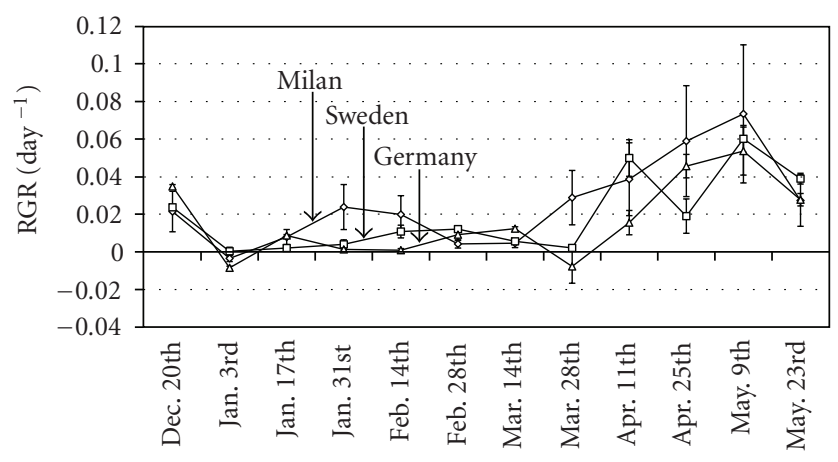

(a)

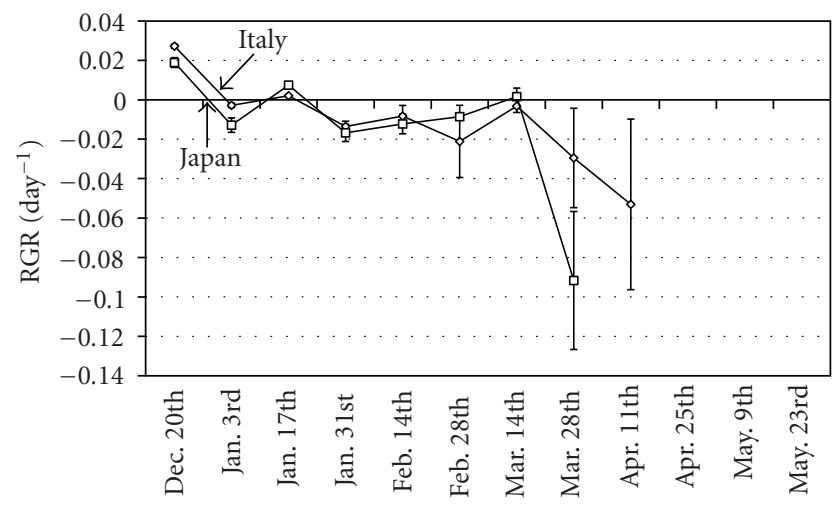

(b)

FIgure 1: Fresh weight RGR (Relative Growth Rate) $=\left(\operatorname{lnw}_{2}-\right.$ $\left.\operatorname{lnw}_{1}\right) /\left(t_{2}-t_{1}\right)$ of the five strains. Experiment started on Dec. 6th 2000. Every RGR is calculated on a two-week period, the end of which is reported in $x$-axis. Bars represent standard deviation. (a) A progressive decrease of leaf dimensions was registered in all strains, associated with accumulation of anthocyanins.

Propanil, 150 and $200 \mathrm{~g} \mathrm{ha}^{-1}$ for Cinosulfuron. A randomized block design with three replications was used, including three vessels and three tanks for control.

For the water floating samples, after drying on blotting paper, the biomass was weighed. For the humid soil sample, biomass variations were estimated from measurements of total leaf surface area. Both, weigh and estimation where made after 7 and 15 days.

Nitrogen and Carbon analyses were carried out as described before.

\section{Results}

3.1. Experiment 1 (Winter Low Temperature Resistance). Biomass increase, rates of growth (RGR) and survival at winter temperatures of the five strains from Dec. 2000 to May 2001 are shown in Figure 1.

A progressive decrease of leaf dimensions was registered in all strains, associated with accumulation of anthocyanins. As time passed, the Japan and Italy strains assumed a tawny colour (an indicator of drying preceding death). After 126 days from the beginning of the experiment, on the Apr. 11th 2001, these strains were eliminated from the experiment.
Table 1: Means and Standard Deviations of Carbon and Nitrogen contents (d.w.\%) and C/N ratio in Azolla strains from Dec. 2000 to May 2001. We observed high quantities of Nitrogen in the leaves of the Japan and Italy strains; it was probably related to the decrease of its biomass during our test. The Milan strain showed lower Nitrogen content, but a good $\mathrm{C} / \mathrm{N}$ ratio associated with a high RGR (see Figure 1).

\begin{tabular}{lcccc}
\hline Strains & & $\% \mathrm{C}$ & $\% \mathrm{~N}$ & $\mathrm{C} / \mathrm{N}$ \\
\hline \multirow{2}{*}{ Milan } & mean & 38.854 & 2.581 & 15.582 \\
& std & 1.66 & 0.48 & 2.58 \\
\multirow{2}{*}{ Sweden } & mean & 37.722 & 2.097 & 18.166 \\
& std & 2.04 & 0.18 & 1.73 \\
Germany & mean & 38.244 & 2.248 & 17.165 \\
& std & 1.87 & 0.18 & 1.60 \\
\multirow{2}{*}{ Italy } & mean & 40.374 & 2.631 & 15.606 \\
& std & 0.98 & 0.33 & 2.08 \\
Japan & mean & 41.294 & 3.025 & 14.336 \\
& std & 1.26 & 0.59 & 3.66 \\
\hline
\end{tabular}

TABLE 2: Temperatures and $\mathrm{RH} \%$ during the course of the experiment, from Mar 22nd to Apr. 28th 2002. Increase of Azolla biomass is somewhat dependent on air humidity as at less than $60 \%$ of relative humidity, the fern becomes dehydrated and fragile. During the experiment, the $\mathrm{RH} \%$ dipped below this critical level for a brief period.

\begin{tabular}{lcccc}
\hline Period & $\begin{array}{c}\text { Mean T } \\
{ }^{\circ} \text { C day }\end{array}$ & $\begin{array}{c}\text { Mean T } \\
{ }^{\circ} \text { C night }\end{array}$ & $\begin{array}{c}\text { Mean } \\
\text { RH\% day }\end{array}$ & $\begin{array}{c}\text { Mean RH\% } \\
\text { night }\end{array}$ \\
\hline 22 Mar.-29 Mar. & 11.7 & 7.8 & 71.1 & 78.4 \\
30 Mar.-05 Apr. & 10.4 & 7.4 & 71.4 & 84.2 \\
06 Apr.-12 Apr. & 12.0 & 8.9 & 64.5 & 79.1 \\
13 Apr.-19 Apr. & 12.0 & 10.1 & 76.1 & 84.1 \\
20 Apr.-26 Apr. & 18.0 & 14.3 & 56.5 & 67.3 \\
\hline
\end{tabular}

By the second half of April, the leaf dimensions of the remaining strains were comparable to those at the outset of the experiment, with the leaves of the Milan strain bigger than those of the Sweden and Germany strains.

Temperature and biomass increase were clearly correlated $\left(r=0.6^{* *}-0.7^{* *}\right)$ for the Milan and Germany strains whereas the correlation index for the Sweden strain is lower and not significant.

Table 1 shows Carbon and Nitrogen content, and $\mathrm{C} / \mathrm{N}$ ratios in Azolla strains. We observed high quantities of nitrogen in the leaf of the Japan and Italy strains, which appeared to be related to the decrease of its biomass during our test. The Milan strain showed lower nitrogen content, but a good C/N ratio associated with a high RGR (Figure 1).

3.2. Experiment 2 (Spring Growth Analysis on Milan Strain). Fern biomass increased linearly from March 22nd to April 19th (28 days), followed by a more rapid growth until April 28th (Figure 2).

Table 2 shows the mean temperatures and $\mathrm{RH} \%$ during the course of the experiment. Increase of Azolla biomass is somewhat dependent on air humidity, as at less than $60 \%$ 
Table 3: Herbicide treatment, Analysis of Nitrogen and Carbon, expressed as d.w. \% and fern morphology. Azolla treated directly with herbicides becomes generally stressed, with an associated decrease in $\mathrm{N}$ and $\mathrm{C}$ content until death ensues. Treatments with $6 \mathrm{~L} / \mathrm{ha}$ of Propanil and Oxadiazon were, from the outset, deleterious for Nitrogen and Carbon accumulation. Treatment with $200 \mathrm{~g} / \mathrm{ha}$ of Cinosulfuron initially caused no change or only a slight increase in Nitrogen and Carbon content. At 13 days, the fresh weight of the samples treated with Cinosulfuron, had shown slight increase of biomass (initial inoculum $=20 \mathrm{~g}$ on Mar. 29th). However, after this intermediate phase Cinosulfuron caused a progressive deterioration leading to the death of the fern. Only Propanil $6 \mathrm{~L} \mathrm{ha}^{-1}$ treatment allowed $60 \%$ of plants to survive, albeit with reduced quantities of fixed Nitrogen. Leaflet surface: $1>2>3>4$. We could weigh only floating samples, in Cinosulfuron treatment. The results of ANOVA (data not showed) performed on the nitrogen and carbon content and their ratio, in the herbicide treated samples show significant difference between treatments for the nitrogen and carbon contents, while differences in $\mathrm{C} / \mathrm{N}$ ratios are less marked. Table shows LSD (Least Significant Difference).

\begin{tabular}{|c|c|c|c|c|c|c|c|c|c|c|c|}
\hline \multirow{2}{*}{ Samples/treatment } & \multicolumn{2}{|c|}{ Apr. 3rd } & \multicolumn{3}{|c|}{ Apr. 10th } & \multicolumn{6}{|c|}{ Apr. 17th } \\
\hline & $\begin{array}{c}\text { Dead } \\
\text { plant \% }\end{array}$ & $\begin{array}{c}\text { Leaflet } \\
\text { dimension }\end{array}$ & $\begin{array}{c}\text { Dead } \\
\text { plant } \%\end{array}$ & Weight & $\begin{array}{c}\text { Leaflet } \\
\text { dimension }\end{array}$ & $\begin{array}{c}\text { Dead } \\
\text { plant \% }\end{array}$ & $\begin{array}{c}\mathrm{N} \\
\text { mean }\end{array}$ & $\begin{array}{c}\text { Std } \\
\%\end{array}$ & $\begin{array}{c}\mathrm{C} \\
\text { mean }\end{array}$ & $\begin{array}{c}\text { Std } \\
\%\end{array}$ & $\begin{array}{l}\mathrm{C} / \mathrm{N} \\
\text { mean }\end{array}$ \\
\hline W/O treatment on wet soil & 0 & 1 & 0 & - & 1 & 0 & 3.6 & 6.0 & 32.4 & 5.1 & 9.0 \\
\hline OXADIAZON $2 \mathrm{~L} \mathrm{ha}^{-1}$ on wet soil & 0 & 3 & $>50$ & - & 3 & 100 & 2.1 & 4.8 & 26.3 & 2.7 & 12.5 \\
\hline PROPANIL $6 \mathrm{~L} \mathrm{ha}^{-1}$ on wet soil & $<10$ & 2 & $<20$ & - & 2 & 40 & 1.8 & 16.7 & 23.6 & 14.0 & 13.1 \\
\hline PROPANIL $12 \mathrm{~L} \mathrm{ha}^{-1}$ on wet soil & $>50$ & 4 & 90 & - & 4 & 100 & 2.5 & 8.4 & 27.5 & 6.9 & 11.2 \\
\hline $\mathrm{W} / \mathrm{O}$ treatment, floating & 0 & 1 & 0 & $44 \mathrm{~g}$ & 1 & 0 & 3.2 & 6.2 & 35.5 & 5.9 & 11.1 \\
\hline CINOSULFURON $150 \mathrm{~g} \mathrm{ha}^{-1}$, floating & 0 & 1 & 50 & $27 \mathrm{~g}$ & 1 & 100 & 3.4 & 5.1 & 37.1 & 3.8 & 10.9 \\
\hline CINOSULFURON $200 \mathrm{~g} \mathrm{ha}^{-1}$, floating & 0 & 1 & 50 & $21 \mathrm{~g}$ & 1 & 80 & 3.8 & 1.5 & 38.3 & 1.2 & 10.2 \\
\hline LSD & & & & & & & 1.41 & & 6.1 & & \\
\hline
\end{tabular}

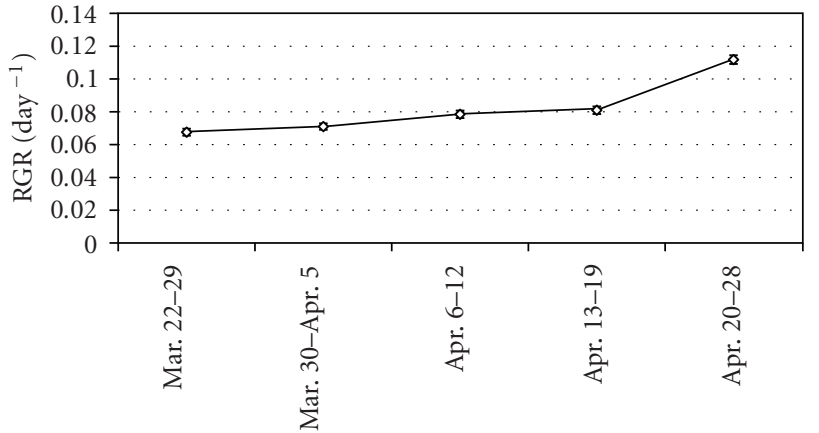

FIGURE 2: Increase of Azolla biomass of Milan strain, expressed as f.w. RGR (Relative Growth Rate) $=\left(\operatorname{lnw}_{2}-\ln w_{1}\right) /\left(t_{2}-t_{1}\right)$, calculated every seven days from Mar. 22nd to Apr. 28th 2002. Every period of which RGR is calculated, is reported on $x$-axis. The extreme of the date intervals is included. The bars represent the standard deviation. Fern biomass increased linearly until 19 April, followed by a more rapid growth until 28 April.

relative humidity, the fern becomes dehydrated and fragile. During the experiment, the RH\% dipped below this critical level for a brief period.

The growth rate measurements are important in the estimation of the amount of Azolla required to inoculate rice paddies and to provide a sufficient nitrogen contribution (25-30 $\left.\mathrm{Kg} \mathrm{ha}^{-1}\right)$.

Assuming inoculation two months before rice seeding in March, and growth rates comparable to those obtained here, to give a cover of 15 tha $^{-1}$ (fresh weight), an inoculum of $600 \mathrm{~kg}$ (f.w.) would be required per hectare of rice paddy. Such an inoculum would necessitate approximately $450 \mathrm{~m}^{2}$ of "nursery bed" surface area. However, when surface area is limiting, the fern will often grow as two or even three layers, potentially allowing the use of a nursery area around 100 meters in length and two meters wide. Finally, it should be noted that this study was performed during a relatively cold spring season. It can thus be assumed that Azolla growth would often be faster than that observed in this study.

3.3. Experiment 3 (Herbicide Resistance). The results of ANOVA performed on the nitrogen and carbon content and their ratios, in the herbicide treated samples, show that significant differences between treatments were noticeable for the nitrogen and carbon contents, while differences in $\mathrm{C} / \mathrm{N}$ ratios are less marked.

Herbicide treatments (Table 3) generally caused stress, with an associated fall in $\mathrm{N}$ and $\mathrm{C}$ content until death ensued. Treatments with $6 \mathrm{~L} / \mathrm{ha}$ of Propanil and Oxadiazon were, from the outset, deleterious for nitrogen and carbon accumulation. Treatment with $200 \mathrm{~g} / \mathrm{ha}$ of Cinosulfuron initially caused no change or only a slight increase in nitrogen and carbon content. At 13 days, the fresh weight of the samples treated with Cinosulfuron had shown slight increase of biomass in respect to initial inoculum. However, after this intermediate phase, Cinosulfuron caused a progressive deterioration leading to the death of the fern. Only Propanil $6 \mathrm{~L} \mathrm{ha}^{-1}$ treatment allowed $60 \%$ of plants to survive, albeit with reduced quantities of nitrogen fixed.

We could weigh only floating samples in the Cinosulfuron treatment, while for Propanil and Oxadiazon, we decided to divide the leaflet surface area into four categories (from 1 to 4 where $1>2>3>4$ ). The results of ANOVA (data not shown) performed on the nitrogen and carbon contents and their ratios in the herbicide treated samples show significant differences between treatments for the nitrogen and carbon contents $(P \leq .01)$, while differences in $\mathrm{C} / \mathrm{N}$ ratios are less marked. 


\section{Discussion}

This research presents a first attempt to evaluate the possibility of using Azolla-Anabaena in rice fields in the Po Valley, as a source of easily mineralized organic Nitrogen.

The information available from the literature was not very useful because the climatic conditions where experiments have been performed (in Asia) are generally extremely different from those in the Po Valley. It was therefore considered necessary to use strains adapted to high latitudes and to local agricultural practices. Results from these preliminary tests allow us to form several conclusions regarding the potential use of this fern.

We show that Azolla-Anabaena is capable not only of surviving low winter temperatures, but of subsequently growing fast enough in order to produce a suitable inoculum for rice paddies in the spring.

The calculation of growth rate allowed us to determine the amount of inoculum required to allow complete coverage of flooded paddies by the time of rice sowing. We have shown that an inoculation of $600 \mathrm{~kg}$ of Azolla, which covers approximately $450 \mathrm{~m}^{2}$ of surface, in March, is capable of producing $15 \mathrm{t}$ of biomass in May, sufficient for complete coverage of 1 ha. As the fern is capable of growing two or three layers deep, it can also produce the same biomass also when less surface area is available and the addition of a little heat to the nursery (e.g., greenhouse) could also boost growth.

Our results were obtained with a strain particularly well adapted to local climatic conditions. This was verified in the comparative test in which 5 strains of various origins were compared. Although the 4 strains supplied by the IRRI are all recognized as cold resistant, adapted to continental climates or to cold winters, our results indicate that only the Milan strain is likely to be capable of surviving Northern Italian winter conditions. We show that this strain produces a reasonable nitrogen content $(2.5-3.5 \%$ d.w.) with $\mathrm{C} / \mathrm{N}$ ratios allowing mineralization $(\mathrm{C} / \mathrm{N}=15)$. The Milan strain was therefore used in a herbicide resistance study. Treatments with the commonly used herbicides Propanil, Oxadiazon, and Cinosulfuron caused the death of the fern. However, the Milan strain survived treatment with a lower (but normally used on rice) concentration of Propanil.

The results obtained from these experiments suggest that the use of Azolla in Po Valley conditions has a potential, suggesting that it could be reasonable, especially for organic farms, to adopt this organic fertilizer which is also capable of reducing weed competition and is resistant to water polluted with one of the most commonly used herbicides.

Experiments in phytoremediation could be developed in irrigated pits and channels with elevated concentrations of $\mathrm{P}$ and heavy metals, in order to test the efficiency of Azolla's phosphorus uptake from soil and the capacity to accumulate heavy metals.

From this perspective, the rice field system could be an interesting application, since the large-scale water use and repeated monoculture can in the long-term involve risk of the accumulation of pollutants in the soil.
It is now important to test, in greenhouse and field experiments, the efficacy of double cultivation of Azolla (with rice) for improving crop and soil characteristics.

\section{References}

[1] D. T. Tuan and R. Q. Thuiet, Use of Azolla in rice production in Vietnam. Nitrogen and Rice, IRRI, Los Baños, Philippines, 1979.

[2] I. Watanabe, "Azolla-Anabaena symbiosis-its physiology and use in tropical agriculture," in Microbiology of Tropical Soils and Plant Productivity, Y. R. Dommergues and H. S. Diem, Eds., pp. 169-185, Martinus Nijhoff, The Ague, The Netherlands, 1982.

[3] T. A. Lumpkin and D. L. Plucknett, Azolla as a Green Manure: Use and Management in Crop Production, Westview, Boulder, Colo, USA, 1982.

[4] G. M. Wagner, "Azolla: a review of its biology and utilization," Botanical Review, vol. 63, no. 1, pp. 1-26, 1997.

[5] J. K. Ladha, D. Dawe, T. S. Ventura, U. Singh, W. Ventura, and I. Watanabe, "Long-term effects of urea and green manure on rice yields and nitrogen balance," Soil Science Society of America Journal, vol. 64, no. 6, pp. 1993-2001, 2000.

[6] D. Casanova, J. Goudriaan, M. M. C. Forner, and J. C. M. Withagen, "Rice yield prediction from yield components and limiting factors," European Journal of Agronomy, vol. 17, no. 1, pp. 41-61, 2002.

[7] I. Watanabe, P. A. Roger, J. K. Ladha, and C. van Hove, Biofertilizer Germplasm Collections at IRRI, IRRI, Los Baños, Philippines, 1992.

[8] S. Sundaravarathan and S. Kannaiyan, "Mineralization pattern of nitrogen fixing green manures Sesbania rostrata and Azolla microphylla in wetland rice soil ecosystem and their effect on rice," in Proceeding of National Workshop on Biofertilizers Technology, Recent Developments in Biofertilizers for Rice Based Cropping System, S. Kannaiyan, K. Kumar, and K. Govindarajan, Eds., pp. 149-168, Scientific Publishers, Jodhpur, India, 2004.

[9] N. A. J. Gowda, A. S. Kumaraswamy, T. R. Guruprasad, and P. S. Herle, "Effect of Azolla biofertilizer on the growth and yield of rice in coastal Karnataka," in Proceeding of National Workshop on Biofertilizers Technology, Recent Developments in Biofertilizers for Rice Based Cropping System, S. Kannaiyan, K. Kumar, and K. Govindarajan, Eds., pp. 198-201, Scientific Publishers, Jodhpur, India, 2004.

[10] P. A. Roger, Biology and Management of the Floodwater Ecosystem in Rice Fields, IRRI, Los Baños, Philippines, 1996.

[11] M. Biswas, S. Parveen, H. Shimozawa, and N. Nakagoshi, "Effects of Azolla species on weed emergence in a rice paddy ecosystem," Weed Biology and Management, vol. 5, no. 4, pp. 176-183, 2005. 


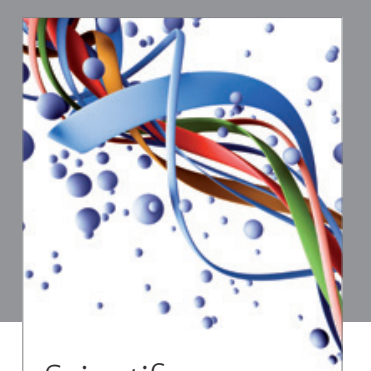

Scientifica
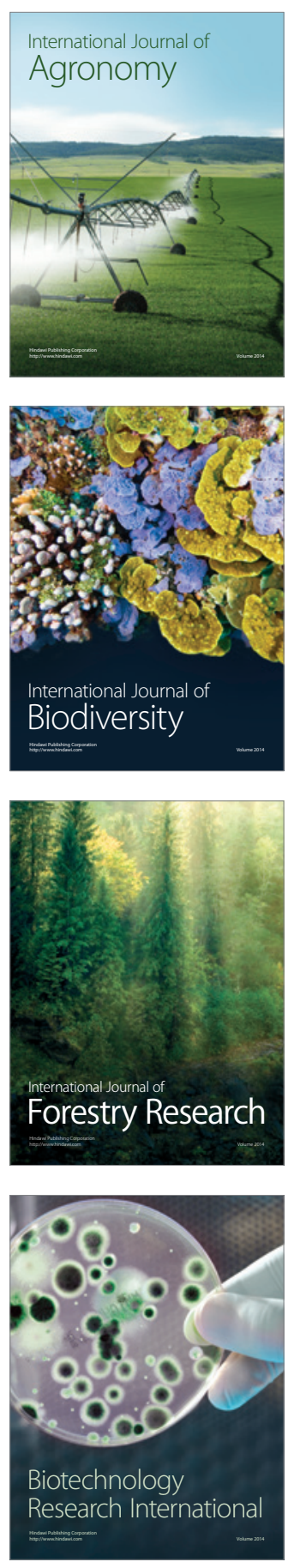
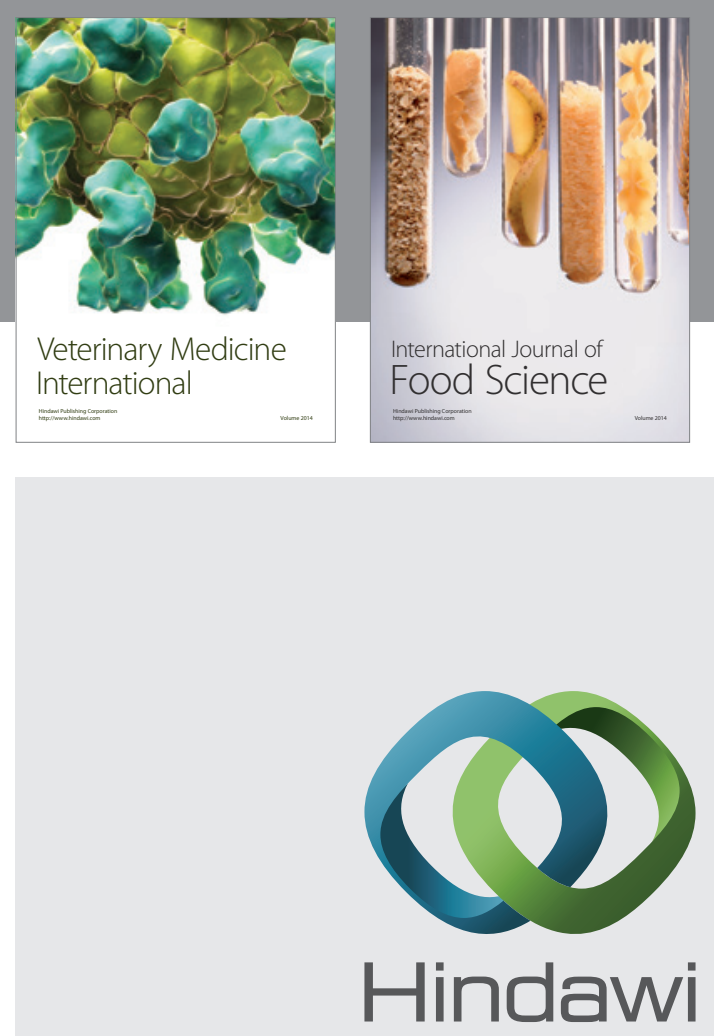

Submit your manuscripts at

http://www.hindawi.com
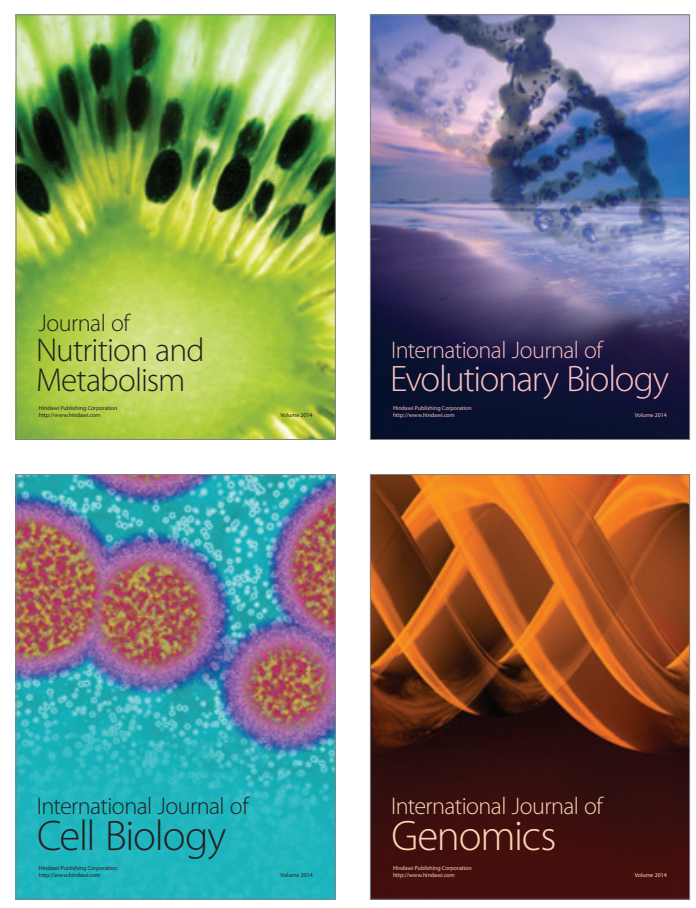
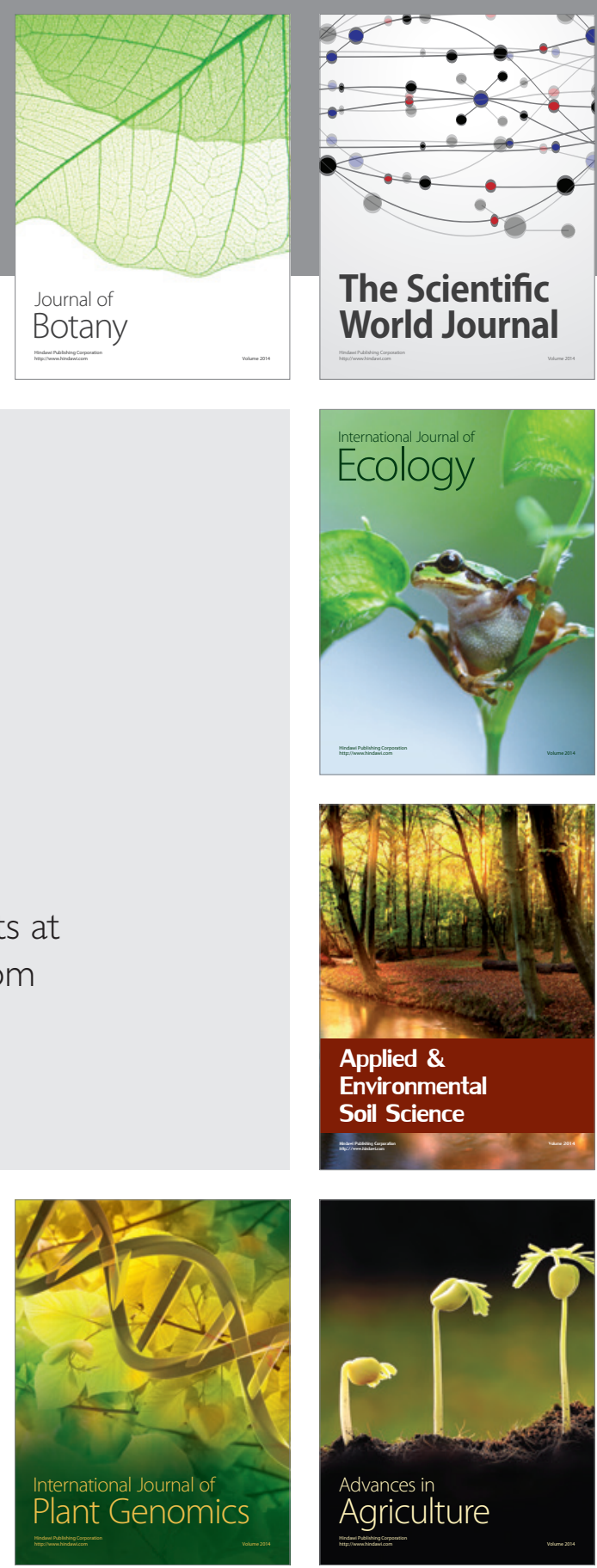

The Scientific World Journal
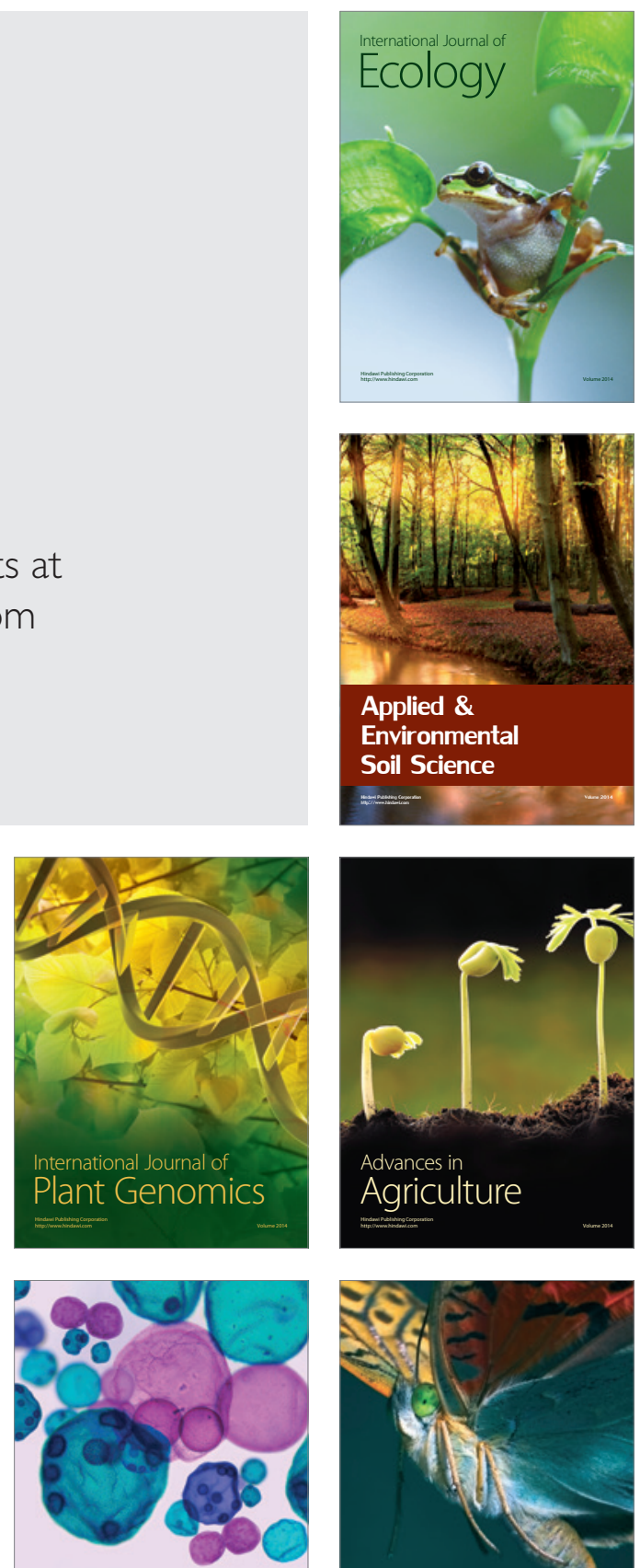

International Journal of Microbiology

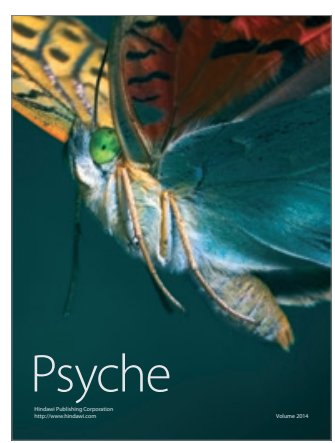

